\title{
Surgical Outcome and Prognostic Factors of Cryptogenic Neocortical Epilepsy
}

\author{
Sang Kun Lee, MD, ${ }^{1}$ Seo Young Lee, MD,${ }^{1}$ Kwang-Ki Kim, MD,${ }^{1}$ Kkeun-Sik Hong, MD, ${ }^{2}$ \\ Dong-Soo Lee, $\mathrm{MD},{ }^{3}$ and Chun-Kee Chung, $\mathrm{MD}^{4}$
}

\begin{abstract}
Surgical treatment of cryptogenic neocortical epilepsy is challenging. The aim of this study was to evaluate surgical outcomes and to identify possible prognostic factors including the results of various diagnostic tools. Eighty-nine patients with neocortical epilepsy with normal magnetic resonance imaging (35 patients with frontal lobe epilepsy, 31 with neocortical temporal lobe epilepsy, 11 with occipital lobe epilepsy, 11 with parietal lobe epilepsy, and 1 with multifocal epilepsy) underwent invasive study and focal surgical resection. Patients were observed for at least 2 years after surgery. The localizing values of interictal electroencephalogram (EEG), ictal scalp EEG, interictal ${ }^{18} \mathrm{~F}$-fluorodeoxyglucose positron emission tomography (FDG-PET), and subtraction ictal single-photon emission computed tomography were evaluated. Seventy-one patients $(80.0 \%)$ had a good surgical outcome (Engel class 1-3); 42 patients were seizure free. Diagnostic sensitivities of interictal EEG, ictal scalp EEG, FDG-PET, and subtraction ictal single-photon emission computed tomography were $37.1 \%, 70.8 \%, 44.3 \%$, and $41.1 \%$, respectively. Localization by FDG-PET and interictal EEG was correlated with a seizure-free outcome. The localizing value of FDG-PET was greatest in neocortical temporal lobe epilepsy. The focalization of ictal onset and also ictal onset frequency in invasive studies were not related to surgical outcome. Concordance with two or more presurgical evaluations was significantly related to a seizure-free outcome.
\end{abstract}

Ann Neurol 2005;58:525-532

Patients with intractable epilepsy recently have benefited from improved surgical procedures. However, most surgical treatments involve medial temporal lobe epilepsy (TLE) and lesional neocortical epilepsy. ${ }^{1}$ Concordant results of electrophysiological and highresolution magnetic resonance imaging (MRI) studies have a high predictive value for surgical outcome. ${ }^{2,3} \mathrm{~A}$ focal structural neuroimaging alteration is usually a reliable indicator of seizure onset. ${ }^{4-6}$ However, MRI is ineffective in $29 \%$ of patients with partial epilepsy, ${ }^{7}$ and many patients referred to epilepsy centers for surgery have normal MRI results. MRI may be unremarkable even in patients with cortical dysplasia. ${ }^{8}$ Previous studies report that surgical outcome is poor for patients with neocortical epilepsy with normal MRI, but these conclusions were based on limited numbers of patients. ${ }^{5,9-12}$ It is important to know not only the surgical prognosis of patients with normal MRI, but also the surgical prognostic factors of these patients. Although noninvasive studies such as ictal single-photon emission computed tomography (SPECT), positron emission tomography (PET), and ictal SPECT provide important presurgical information, these modalities rarely have been compared with surgical outcome.

Intracranial monitoring is indispensable for neocortical epilepsy with normal MRI, but it is limited by insufficient sampling. Furthermore, the intracranial ictal onset pattern itself may also be important. A variety of electrographic intracranial seizure onset patterns are known. ${ }^{13-16}$ However, the first electrographic change does not always indicate a true ictal onset zone, and some patterns represent a propagated phenomenon. ${ }^{15,16}$ Resection of the area in which the true local intracranial onset lies could improves surgical outcome. Therefore, identification of intracranial ictal onset associated with seizure-free outcome would be useful.

The objectives of this study were to evaluate the surgical outcomes of patients with neocortical epilepsy with normal MRI and to identify prognostic factors including the results of various diagnostic modalities and invasive studies. We also evaluated the diagnostic sensitivities of interictal EEG, ictal scalp EEG, interictal FDG-PET, and subtraction SPECT.
From the ${ }^{1}$ Department of Neurology, Seoul National University College of Medicine, Seoul; ${ }^{2}$ Department of Neurology, Inje University Ilsan Paik Hospital, Ilsan; and Departments of ${ }^{3}$ Nuclear Medicine and ${ }^{4}$ Neurosurgery, Seoul National University College of Medicine, Seoul, Korea.

Received Jan 18, 2005, and in revised form May 5. Accepted for publication Jun 8, 2005.
Published online Jul 21, 2005 in Wiley InterScience (www.interscience.wiley.com). DOI: 10.1002/ana.20569

Address correspondence to Dr Lee, Department of Neurology, Seoul National University Hospital, 28 Yongon-dong, Chongno-gu, Seoul, Korea, 110-744. E-mail: sangunlee@dreamwiz.com 


\section{Patients and Methods}

\section{Patients}

We included 89 consecutive patients without MRIdetectable lesions who underwent focal surgical resection for intractable epilepsy at Seoul National University Hospital from September 1995 to July 2002. The group consisted of 55 men and 34 women with ages ranging from 8 to 56 (mean, $25.6 \pm 7.9$ ) years. Age at seizure onset ranged from 2 to 49 (mean, $6.8 \pm 6.1$ ) years, and the duration of illness from 3 to 28 (mean, $13.5 \pm 6.5$ ) years. All patients had intractable epilepsy despite proper anticonvulsant medication. Follow-up for patients continued for at least 2 years after surgery (mean, $3.54 \pm 1.85$ ). We included only patients with focal resection and excluded patients with functional hemispherectomy, corpus callosotomy, hippocampal sclerosis on MRI, or medial temporal intracranial ictal onset zone.

\section{Magnetic Resonance Imaging}

All patients underwent brain MRI. Standard MRI was performed on either a 1.0-or a 1.5-Tesla unit (Signa Advantage; General Electric Medical Systems, Milwaukee, WI) with conventional spin-echo T1-weighted sagittal and T2weighted axial and coronal sequences in all patients. Section thickness and conventional image gaps were 5 and $1 \mathrm{~mm}$, respectively. In addition, T1-weighted three-dimensional magnetization prepared rapid acquisition with gradient-echo sequences and $1.5 \mathrm{~mm}$-thick sections of the whole brain, and T2-weighted and fluid-attenuated inversion recovery images with $3 \mathrm{~mm}$-thick sections were obtained in the oblique coronal plane of the temporal lobe. The angle of the oblique coronal imaging was perpendicular to the long axis of the hippocampus. Spatial resolution was approximately $1.0 \times$ $1.0 \mathrm{~mm}$ (matrix, $256 \times 256 \mathrm{~mm}$; field of view, $25 \mathrm{~cm}$ ).

\section{Functional Neuroimaging}

PET was performed in 79 patients during the interictal period (no seizures for more than 24 hours). Axial raw data were obtained using a PET scanner (ECAT EXACT 47; Siemens-CTI, Knoxville, TN) 60 minutes after the intravenous injection of ${ }^{18} \mathrm{~F}$-fluorodeoxyglucose (FDG; $370 \mathrm{MBq}) .{ }^{17}$ Spatial resolution was $6.1 \times 6.1 \times 4.3 \mathrm{~mm}$. FDG-PET images were assessed visually and by Statistical Parametric Mapping (SPM) analysis as described previously. ${ }^{17}$ Ictal SPECT was performed on 56 patients during video-EEG monitoring. ${ }^{99 \mathrm{~m}} \mathrm{Tc}$ was mixed with hexamethylpropyleneamine oxime $(925 \mathrm{MBq})$ and injected as soon as a seizure started. Brain SPECT images were acquired within 2 hours of administering the injection. ${ }^{17} \mathrm{~A}$ triplehead rotating Gamma camera (Prism 3000; Picker, Cleveland, $\mathrm{OH}$ ) equipped with a high-resolution fan beam collimator was used. Interictal SPECT was also performed to identify perfusion changes. Side-by-side visual analysis of interictal and ictal images and the subtraction method were performed by the method described previously. ${ }^{17}$

\section{Video-Electroencephalographic Monitoring}

Interictal and ictal scalp EEGs were recorded using a videoEEG monitoring system, with electrodes placed according to the International 10-20 system and with additional anterior temporal electrodes. We used a combination of grids and strips for intracranial EEG. Grid and strip placements were determined by the results of presurgical evaluations. At least three habitual seizures were recorded during scalp and intracranial EEG monitoring. When necessary, preoperative and intraoperative functional mapping and intraoperative electrocorticography were also performed.

\section{Evaluation of Noninvasive Studies}

Interictal and ictal scalp EEGs were reviewed and classified by two epileptologists after consensus had been reached. A localizing pattern of ictal-onset rhythm/interictal spike was defined as a localized ictal rhythm/interictal spike confined to the electrodes of an epileptogenic lobe or two adjacent electrodes.

FDG-PET analyzed by SPM and ictal-interictal subtraction SPECT were reviewed by one experienced physician who was unaware of the results of other presurgical evaluations. The SPECT images were also evaluated using side-byside visual analysis. Results of FDG-PET and SPECT were defined as localizing when the predominant hyperperfusion area or the predominant hypometabolic zone was confined to the resected lobe.

\section{Invasive Studies}

The "intracranial ictal onset zone" was defined as the area with the first sustained rhythmic change in EEG differentiated from the background and interictal waves. The onset frequency was characterized in traditional EEG bands: $\beta, \alpha$, $\theta$, and $\delta$.

Distribution of seizure onset was categorized as focal (involving $<5$ adjacent electrodes), regional ( $\geq 5$ adjacent electrodes), or widespread ( $>20$ adjacent electrodes).

\section{Surgery and Pathology}

The resection margin was defined by an intracranial ictal onset zone including the area with persistent pathological delta slowing and the location of eloquent cortex. Tissue sections from cortical resections were immersion fixed in $10 \%$ buffered formalin, embedded in paraffin, and stained with hematoxylin and eosin, Bielschowsky stain, and cresyl violet. A diagnosis of pathological cortical dysplasia was classified into mild, moderate, and severe, according to the system of Mischel and colleagues. ${ }^{18}$

\section{Follow-up}

Follow-up information for at least 2 years was available in all patients. Surgical outcomes were classified into four groups according to the Engel classification. ${ }^{1}$ Surgical outcome was also divided into seizure free and nonseizure free.

\section{Analysis}

We assessed surgical outcome as a whole and according to the location of the epileptogenic lobe. The accuracy of the presurgical evaluations were evaluated in all patients and in seizure-free patients to exclude the possibility of false localization of epileptogenic foci. To determine the significance of surgical prognostic factors, we performed univariate analyses for age of onset, duration of illness, age at operation, location of epileptogenic foci, localization of interictal EEG, 
Table 1. Surgical Outcome of 89 Patients with Nonlesional Neocortical Epilepsy according to Epileptogenic Focus Location

\begin{tabular}{lccccc}
\hline & & \multicolumn{3}{c}{ Engel Class } \\
\cline { 3 - 5 } Location & $\begin{array}{c}\text { No. of } \\
\text { Patients }\end{array}$ & I & II & III & IV \\
\hline Frontal & 35 & 15 & 1 & 12 & 7 \\
Neocortical temporal & 31 & 17 & 3 & 5 & 6 \\
Parietal & 11 & 3 & 1 & 3 & 4 \\
Occipital & 11 & 7 & 1 & 3 & 0 \\
Multifocal & 1 & 0 & 0 & 0 & 1 \\
Total & 89 & $42(47.2 \%)$ & $6(6.7 \%)$ & $23(25.8 \%)$ & $18(20.2 \%)$ \\
\hline
\end{tabular}

ictal scalp EEG, interictal FDG-PET, ictal subtraction SPECT, and results of invasive study. We also assessed the relation between surgical outcome and the concordance of presurgical evaluations. $\chi^{2}$ or Fisher's exact test was used, depending on the variables tested.

\section{Results}

\section{Surgical Outcome}

Of the patients, 35 had frontal lobe epilepsy (FLE), 31 had neocortical temporal lobe epilepsy (nTLE), 11 had parietal lobe epilepsy (PLE), 11 had occipital lobe epilepsy (OLE), and 1 had multifocal epilepsy. Seventyone patients $(80.0 \%)$ had a good surgical outcome (Engel class 1-3); 42 patients were seizure free (47.2\%). The seizure-free rates for FLE or PLE were less than for nTLE or OLE, but the difference was not significant $(p=0.134$; Table 1$)$.

By univariate analysis, surgical outcome was not related to factors such as age at surgery, sex, age at onset, or duration of illness.

\section{Diagnostic Accuracy and the Prognostic Values of Presurgical Evaluations}

Interictal EEG showed unifocal epileptiform discharges concordant to the resected lobe in 33 of 89 patients $(37.1 \%)$ and in 20 of 42 seizure-free patients (47.6\%) (Table 2). FDG-PET had concordant focal hypometabolism in 35 of 79 patients (44.3\%) and in 23 of 40 seizure-free patients $(57.5 \%)$ (Fig). Subtraction SPECT had concordant focal hyperperfusion in 23 of $56 \mathrm{pa}-$ tients, who underwent ictal and interictal SPECT; it was observed in 10 of 24 seizure-free patients. The mean injection delay of radioligand was $28.5 \pm 17.1$ seconds. Ictal EEG correctly localized the resected lobe in 63 of 89 patients and in 33 of 42 seizure-free patients. Localization by FDG-PET and interictal EEG was significantly related with a seizure-free outcome ( $p=0.042$ and 0.015 , respectively), whereas localization by subtraction SPECT or ictal EEG was not related to a seizure-free outcome.

The localizing value of FDG-PET was greatest in nTLE (Table 3). The focalization of ictal onset and the ictal-onset frequency in invasive studies were not related to outcome (Table 4).
A comparison between the good outcome and poor outcome groups showed that the concordance rate was greater in those with a seizure-free outcome (Table 5). Concordance in 2 or more modalities was found in 29 of 42 seizure-free patients and in 19 of 47 patients who were not seizure free. Concordance between two or more presurgical results was related to a seizure-free outcome $(p=0.006)$.

The roles of FDG-PET and ictal SPECT in the localization of the epileptogenic lobe were complementary. FDG-PET correctly localized the epileptogenic lobe in seven patients with nonlocalizing subtraction SPECT, whereas SPECT correctly localized it in three with nonlocalizing PET.

\section{Pathology}

Pathology specimens were available for 80 patients. There were 58 cases of cortical dysplasia including microdysgenesis, 10 other migration abnormalities, 9 cases of focal neuronal loss with gliosis, and 2 cases of ischemic change. In one patient, moderate cortical dysplasia was associated with a dysembryoplastic neuroepithelial tumor. Pathology results were not related to surgical outcome.

\section{Discussion}

The results indicate that surgical treatment can be of benefit in patients with neocortical epilepsy with normal MRI. Of these patients, $47.2 \%$ were seizure free for at least 2 years after surgery, and $80.0 \%$ had a seizure reduction of least $90 \%$. However, compared with epilepsy with focal abnormal MRI, the relative poor outcome is also noticeable. The good surgical outcome associated with focal abnormal MRI at ictal onset is well known. ${ }^{3,19,20}$ Many studies including a metaanalysis have suggested that the presence of a specific lesion indicates a favorable surgical outcome. ${ }^{12,21-24}$ One multivariate analysis suggests that FLE patients with normal MRI have a poor surgical outcome. ${ }^{25}$ Only 4 of 17 patients became seizure free after surgery. Another report also shows that only $41 \%$ of nonlesional FLE patients had excellent outcomes after surgery. ${ }^{6}$ Three comparable studies have used large numbers of 
Table 2. Diagnostic Accuracy of Presurgical Evaluation and Surgical Outcome

\begin{tabular}{lccr}
\hline $\begin{array}{l}\text { Presurgical Evaluation } \\
\text { (no. of patients) }\end{array}$ & Seizure-free & Persistent Seizure & $p$ \\
\hline Interictal EEG (89) & $20 / 42(47.6 \%)$ & $13 / 47(27.7 \%)$ & 0.042 \\
PET (79) & $23 / 40(57.5 \%)$ & $12 / 39(30.8 \%)$ & 0.015 \\
Ictal SPECT (56) & $10 / 24(41.7 \%)$ & $3 / 32(40.6 \%)$ & 0.577 \\
Ictal scalp EEG (89) & $33 / 42(78.6 \%)$ & $30 / 47(63.8 \%)$ & 0.098 \\
\hline
\end{tabular}

${ }^{a}$ Focal abnormality compatible with a resected area or lobe.

EEG = electroencephalogram; PET $=$ position emission tomography; SPECT $=$ single-photon emission computed tomography.

patients with normal MRI. ${ }^{26-28}$ One of these shows that only $37 \%$ of patients with intractable nonlesional focal epilepsy were seizure free after surgery. ${ }^{26}$ Another showed that 20 of 24 patients with normal MRI who had focal intracranial ictal onset zone had a good surgical outcome. ${ }^{27}$ However, if patients with normal MRI and no positively identified focal invasive onset are included in the total, only 20 of 43 patients had a good surgical outcome. The correct localization of epileptogenic foci is difficult when no structural lesion is evident on MRI. Characteristics of neocortical epilepsy such as a widespread epileptogenic process, rapid prop- agation of ictal rhythm, and the presence of eloquent areas also contribute to a poor prognosis.

MRI is the most important diagnostic technique for epilepsy surgery. It readily detects focal cortical dysplasia and distinguishes Taylor's focal cortical dysplasia from non-Taylor's focal cortical dysplasia. ${ }^{29}$ However, MRI may be persistently unremarkable even in malformation of cortical developments. High-resolution MRI showed the lesion in only half of the cases. ${ }^{30} \mathrm{We}$ also reported that MRI could miss lesions in 9 of 23 cases with cortical dyslamination and cytomegaly. ${ }^{8}$ MRI may also miss microdysgenesis. MRI was unrevealing in

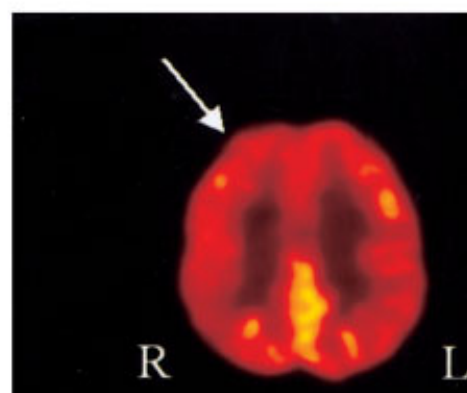

A

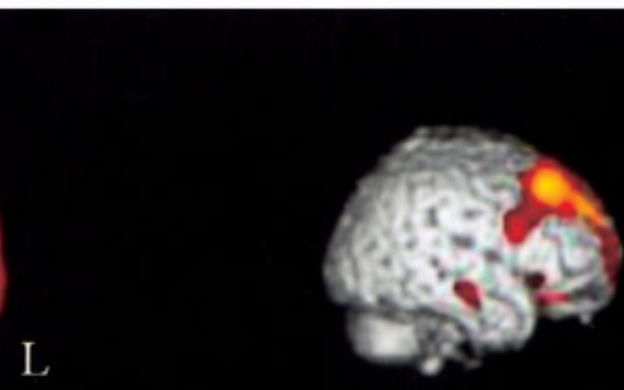

B

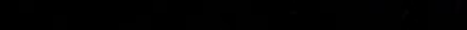

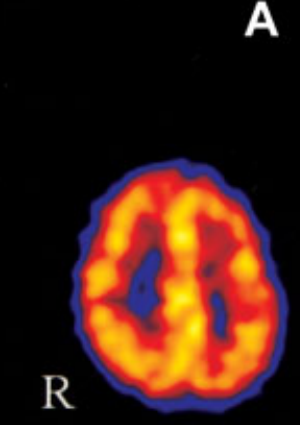

C

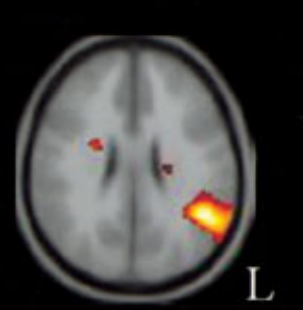

E

Fig. (A, B) A 29-year-old female patient with the nonlesional right frontal lobe epilepsy. (A) ${ }^{18}$ F-fluorodeoxyglucose positron emission tomography (FDG-PET) scans showed right frontal hypometabolism (arrow). (B) Statistical Parametric Mapping image (p = 0.001, uncorrected) also showed right frontal decreased metabolism. (C-E) A 16-year-old female patient with left parietal lobe epilepsy. (C) Interictal single-photon emission computed tomography (SPECT) demonstrated no remarkable hypoperfused area. (D) Ictal SPECT showed focal increased perfusion in the left parietal area. (E) Subtraction SPECT also showed the left parietal hyperperfused area. $L=$ left; $R=$ right. 
Table 3. Localizing Value of Individual Modalities in Seizure-free Patients (42 patients) (number of localizations/no. of patients who received a presurgical evaluation)

\begin{tabular}{lcccc}
\hline & $\begin{array}{c}\text { Interical } \\
\text { EEG }\end{array}$ & $\begin{array}{c}\text { Ictal } \\
\text { EEG }\end{array}$ & PET & $\begin{array}{r}\text { Ictal } \\
\text { SPECT }\end{array}$ \\
\hline Frontal & $7 / 15$ & $12 / 15$ & $4 / 14$ & $3 / 7$ \\
nTemporal & $9 / 17$ & $13 / 17$ & $14 / 16$ & $6 / 8$ \\
Parietal & $0 / 3$ & $1 / 3$ & $1 / 3$ & $0 / 3$ \\
Occipital & $4 / 7$ & $7 / 7$ & $4 / 7$ & $1 / 6$ \\
Subtotal & $20 / 42$ & $33 / 42$ & $23 / 40$ & $10 / 24$ \\
$p^{a}$ & 0.365 & 0.132 & 0.010 & 0.062 \\
\hline
\end{tabular}

${ }^{a}$ By Fisher's exact test: significantly different results according to the involved epileptogenic lobe.

$\mathrm{EEG}=$ electroencephalogram; PET $=$ position emission tomography; $\mathrm{nTemporal}=$ neocortical temporal.

$34 \%$ of patients with microdysgenesis. ${ }^{31}$ High-Tesla MRI, multiplanar reconstruction, curvilinear reformatting, ${ }^{29}$ or high-resolution MRI with the phase-array surface coil may improve the detection rate.

Our study demonstrated high localizing value of ictal scalp EEG. The localizing value of ictal EEG has not been extensively studied in neocortical focal epilepsy. It frequently does not localize and can localize falsely when the focus is circumscribed or in the depths of a sulcus. ${ }^{32-37}$ Many previous studies used small numbers of patients or were confined to specific epileptic syndromes. ${ }^{12,32-39}$ Two studies ${ }^{40,41}$ showed the clinical usefulness of ictal surface EEG for neocortical epilepsies. Ictal EEGs were correctly localized in $50.2 \%$ of extratemporal epilepsy cases and $74.5 \%$ of nTLE cases. ${ }^{40}$ We previously reported that $42 \%$ of ictal EEGs were able to be localized in neocortical epilepsy cases and that $62 \%$ of patients had at least one ictal EEG that could be localized. ${ }^{41}$ The diagnostic sensitivity in our study was calculated based on the number of patients. When we analyzed our data based on the number of EEGs, 238 of 463 ictal scalp EEGs were able to be localized (51.4\%). There should be a selection bias

Table 4. Results of Invasive Studies and Surgical Outcome

\begin{tabular}{lccc}
\hline $\begin{array}{l}\text { Results of Invasive } \\
\text { Study }\end{array}$ & $\begin{array}{c}\text { Seizure-free } \\
(42)\end{array}$ & $\begin{array}{c}\text { Persistent } \\
\text { Seizure (47) }\end{array}$ & $p$ \\
\hline $\begin{array}{l}\text { Onset pattern } \\
\quad \text { (no. of patients) }\end{array}$ & & & \\
Focal (41) & 20 & 21 & 0.626 \\
$\quad$ Regional (47) & 22 & 25 & \\
$\quad$ Widespread (1) & & 1 & \\
Onset frequency & 24 & 30 & 0.544 \\
$\beta$ & 7 & 5 & \\
$\alpha$ & 2 & 4 & \\
$\theta$ & 4 & 6 & \\
$\delta$ & 5 & 2 & \\
Periodic spike and & & & \\
$\quad$ wave & & & \\
\hline
\end{tabular}

Table 5. Comparison of Concordance between the Seizure-free and the Not-Seizure-free Groups

\begin{tabular}{lcc}
\hline $\begin{array}{l}\text { Concordance } \\
\text { (no. of patients) }\end{array}$ & $\begin{array}{c}\text { Seizure-free } \\
(42)\end{array}$ & $\begin{array}{c}\text { Not } \\
\text { seizure-free } \\
(47)\end{array}$ \\
\hline Four modalities (5) & 4 & 1 \\
Three modalities (18) & 10 & 8 \\
Two modalities (25) & 15 & 10 \\
One modality (28) & 9 & 19 \\
All nonlocalizing (13) & 4 & 9 \\
\hline
\end{tabular}

underlying this high diagnostic sensitivity, because patients with localized ictal EEG could have been recruited more easily for surgery, especially in the absence of a structural lesion. Our inclusion criteria (normal MRI) may also have played a role. The presence of structural lesions may hamper the correct localization because a large structural lesion or cerebromalacia can limit the number of neurons firing at the start of a seizure.

Surgery was effective when the majority of scalprecorded seizures arose from the resected lobe. ${ }^{26}$ However, despite the high localizing value of ictal scalp EEG in our study, the localization itself did not predict surgical outcome.

Patients with focal interictal spikes in the neocortical epileptogenic area are a minority. ${ }^{34,39,42}$ Although the diagnostic sensitivity of interictal EEG was low in our study, the presence of focal interictal spikes was associated with a good surgical outcome. Poor outcome was reported to be predicted by the presence of spikes distant from the resected lobe, multiple spikes, or generalized spike and wave. ${ }^{26}$

FDG-PET localized the epileptogenic lobe in $44.3 \%$ of our patients. Some authors have emphasized the minimal yield of PET in neocortical epilepsies when MRI is negative. ${ }^{43-47}$ However, a recent study based on 462 cases demonstrates that $32 \%$ of normal MRIs were associated with an abnormal PET scan. ${ }^{48}$ FDGPET demonstrated hypometabolism in 12 of 13 children with FLE with normal MRI and microdysgenesis. ${ }^{49}$ Focal hypometabolism was also found in a small number of children with cryptogenic infantile spasms with microdysgenesis. ${ }^{50}$ These findings suggest that FDG-PET is useful for patients with neocortical epilepsy with normal MRI, which confirms our results.

The SPM technique yields better FDG-PET results than visual analysis. ${ }^{51}$ We used both analyses to detect focal hypometabolism; this may partially have influenced the high sensitivity of FDG-PET. A recent report shows that 26 of 30 patients with TLE without hippocampal sclerosis had concordant FDG-PET lateralization. $^{52}$ The high incidence of abnormal metabolism in neocortical TLE may also have affected our results. 
FDG-PET localization was significantly related with a seizure-free outcome. The relation between focal hypometabolism in neocortical epilepsy and surgical outcome has not been studied extensively. The presence of unilateral temporal lobe hypometabolism, even when MRI is normal, predicts a good surgical outcome in more than $80 \%$ of cases. ${ }^{53}$

The diagnostic sensitivity (41.1\%) of subtraction SPECT was less than expected. Prior literature demonstrated that subtraction ictal SPECT was valuable in the localization of neocortical epilepsy. ${ }^{45,54}$ Subtraction periictal SPECT showed localized hyperperfusion in 66.7 to $86 \%$ of neocortical epilepsy cases even in the absence of lesions on MRI. ${ }^{54,55}$ The localization of subtraction SPECT was reported to be predictive of surgical outcome. ${ }^{56}$ However, these authors included two-lobar patterns such as parietooccipital or frontotemporal hyperperfusion in the "localizing" group. We classified this as "lateralizing" pattern. Our criterion for "localizing" was the presence of a predominant hyperperfused area in the one epileptogenic lobe. When we included these "lateralizing" patterns into the "localizing" group, 18 of 24 seizure-free patients $(75.0 \%)$ and 35 of all 56 patients (62.5\%) had "localizing" SPECT. This result is comparable with those of other patients. The lateralizing pattern was the image of propagated ictal activity, which is often observed in extratemporal seizures. ${ }^{17,57-59}$ Propagation of ictal activity partly explains variation in sensitivity and specificity with different thresholds of subtraction SPECT. ${ }^{60}$ Our fixed threshold may have affected the results. Even when we included the "lateralizing" pattern in the "localizing" group, the predictive value of subtraction SPECT for good surgical outcome was only marginally significant ( $p=0.081$, Fisher's exact test). Inclusion of greater numbers will resolve this issue.

Neocortical epilepsy cases showed a lower concordance rate between diagnostic modalities than mesial TLE cases. This is partly due to the lower sensitivities of all diagnostic methods in these patients. ${ }^{61-63}$ The presence of concordance between diagnostic methods means that the localized lesion shows its abnormality through different physiological mechanisms. This implies that there is a greater possibility that the colocalized lesion is an epileptogenic zone. Although the concordance of these diagnostic modalities was important for predicting surgical outcome in our trial, the complementary roles of FDG-PET and subtraction SPECT were also evident. Multimodal evaluations thus are indicated for these patients. However, they sometimes localize falsely or lateralize, and caution should be exercised when interpreting results. ${ }^{17}$

Intracranial low-voltage fast activity at seizure onset may be associated with good surgical outcomes. ${ }^{13,14,64}$ A slower frequency ictal onset may represent a propagated electrographic pattern or a larger epileptogenic zone. ${ }^{14-16}$ Some authors have argued that low-voltage localized $\beta$ activity is a marker of the site of seizure onset, ${ }^{65-68}$ but others have disputed this. ${ }^{15,16} \mathrm{We}$ also found that the most common early intracranial ictal discharge is low-amplitude $\beta$ activity. However, we did not detect a relation between the frequency and surgical outcome. It is also held that spatial restriction is characteristic of an intracranial ictal onset close to a true ictal onset zone. In contrast, regional onset might imply volume conduction or propagation from a distant generator. ${ }^{69-72}$ However, we could not detect a relation between the focalization of intracranial ictal rhythm and surgical outcome.

Although we did not observe a definite relation between the location of epileptogenic foci and surgical outcome, the location appears to affect surgical outcome. When we regrouped patients into the classes, FLE/PLE and nTLE/OLE, and surgical outcomes into Engel classes $1 / 2$ and $3 / 4$, the relation between the location of epileptogenic foci and surgical outcome was significant $(p=0.024)$. The limitations of complete resection caused by eloquent areas and the difficulty of sufficient intracranial sampling of the medial and orbitofrontal areas may be related to poor outcome in FLE. Semiologic inconsistencies in PLE, low-yield diagnostic modalities, and presence of eloquent areas in nonlesional PLE $\mathrm{PL}^{73-75}$ also contribute to poor prognosis.

Surgical treatment can benefit patients with nonlesional neocortical epilepsy, and presurgical evaluations can correctly localize the epileptogenic lobe in these patients. The focal hypometabolism on FDG-PET, focal interictal spikes, and concordance of the presurgical evaluations can be used to predict good surgical outcome.

\section{References}

1. Engel J Jr, Van Ness P, Rasmussen T, Ojemann LM. Outcome with respect to epileptic seizures. In: Engel J Jr, ed. Surgical treatment of the epilepsies. 2nd ed. New York: Raven Press, 1993:609-622.

2. Bronen RA. Epilepsy: the role of MR imaging. Am J Radiol 1992;159:1165-1174.

3. Cascino GD, Boon PA, Fish DR. Surgically remediable lesional syndrome. In: Engel J Jr, ed. Surgical treatment of the epilepsies. 2nd ed. New York: Raven Press, 1993:77-86.

4. Radhakrishnan K, So EL, Silbert PL, et al. Predictors of outcome of anterior temporal lobectomy for intractable epilepsy: a multivariate study. Neurology 1998;51:465-471.

5. Cascino GD. Surgical treatment for extratemporal epilepsy. Curr Treat Options Neurol 2004;6:257-262.

6. Mosewich RK, So EL, O’Brien TJ, et al. Factors predictive of the outcome of frontal lobe epilepsy surgery. Epilepsia 2000;41: 843-849.

7. Semah F, Picot MC, Adam C, et al. Is the underlying cause of epilepsy a major prognostic factor for recurrence? Neurology 1998;51:1256-1262.

8. Lee SK, Choe G, Hong KS, et al. Neuroimaging findings of cortical dyslamination with cytomegaly. Epilepsia 2001;42: $850-856$. 
9. Cascino GD, Jack CR Jr, Parisi JE, et al. MRI in the presurgical evaluation of patients with frontal lobe epilepsy and children with temporal lobe epilepsy: pathological correlation and prognostic significance. Epilepsy Res 1992;11:51-59.

10. Cascino GD, Kelly PJ, Hirschorn KA, et al. Stereotaxic resection of intraaxial cerebral lesions in partial epilepsy. Mayo Clin Proc 1990;65:1053-1060.

11. Lorenzo NY, Parisi JE, Cascino GD, et al. Intractable frontal lobe epilepsy: pathological and MRI features. Epilepsy Res 1995;20:171-178.

12. Zetner J, Hufnagel A, Ostertun B, et al. Surgical treatment of extratemporal epilepsy: clinical, radiological, and histological findings in 60 patients. Epilepsia 1996;37:1072-1080.

13. Alacron G, Binnie CD, Elwes RDC, Polkey CE. Power spectrum and intracranial EEG patterns at seizure onset in partial epilepsy. Electroencephalogr Clin Neurophysiol 1995;94: 326-337.

14. Faught E, Kuzniecky RI, Hurst DC. Ictal EEG waveforms from epidural electrodes predictive of seizure control after temporal lobectomy. Electroencephalogr Clin Neurophysiol 1992;9: 441-448.

15. Lee SA, Spencer DD, Spencer SS. Intracranial EEG seizureonset patterns in neocortical epilepsy. Epilepsia 2000;41: 297-307.

16. Schiller Y, Cascino GD, Busacker NE, Shabrough FW. Characterization and comparison of local onset and remote propagated electrographic seizures recorded with intracranial electrodes. Epilepsia 1998;39:380-388.

17. Lee $\mathrm{SK}$, Yun $\mathrm{CH}, \mathrm{Oh} \mathrm{JB}$, et al. Intracranial ictal onset zone in non-lesional lateral temporal lobe epilepsy on scalp ictal EEG. Neurology 2003;61:757-764.

18. Mischel PS, Nguyen LP, Vinters HV. Cerebral cortical dysplasia associated with pediatric epilepsy: review of neuropathologic features and proposal for a grading system. J Neuropath Exp Neurol 1995;54:137-153.

19. Fried I, Cascino GD. Lesional surgery. In: Engel J Jr, ed. Surgical treatment of the epilepsies. 2nd ed. New York: Raven Press, 1993:501-509.

20. Awad IA, Rosenfield J, Ahl J, et al. Intractable epilepsy and structural lesion of the brain: mapping, resection strategies, and seizure outcome. Epilepsia 1991;32:179-186.

21. Duncan JS, Sagar HJ. Seizure characteristics, pathology, and outcome after temporal lobectomy. Neurology 1987;37: 405-409.

22. Berkovic SF, McIntosh AM, Kalnins RM, et al. Preoperative MRI predicts outcome of temporal lobectomy: an acturial analysis. Neurology 1995;45:1358-1363.

23. Spencer SS. Long-term outcome after epilepsy surgery. Epilepsia 1996;37:807-813.

24. Tonini C, Beghi E, Berg AT, et al. Predictors of epilepsy surgery outcome: a meta-analysis. Epilepsy Res 2004;62:75-87.

25. Ferrier CH, Engelsman J, Alarcon G, et al. Prognostic factors in presurgical assessment of frontal lobe epilepsy. J Neurol Neurosurg Psychiatry 1999;66:350-356.

26. Blume WT, Ganapathy GR, Munoz D, Lee DH. Indices of resective surgery effectiveness for intractable nonlesional focal epilepsy. Epilepsia 2004;45:46-53.

27. Siegel AM, Jobst BC, Thadani VM, et al. Medically intractable, localization-related epilepsy with normal MRI: presurgical evaluation and surgical outcome in 43 patients. Epilepsia 2001;42: 883-888.

28. Hong KS, Lee SK, Kim JY, et al. Pre-surgical evaluation and surgical outcome of 41 patients with non-lesional neocortical epilepsy. Seizure 2002;11:184-192.
29. Colombo N, Tassi L, Galli C, et al. Focal cortical dysplasias: MR imaging, histopathologic, and clinical correlations in surgically treated patients with epilepsy. AJNR Am J Neuroradiol 2003;24:724-733.

30. Montenegro MA, Li LM, Guerreiro MM, et al. More sensitive MRI techniques for detecting focal cortical dysplasia. J Neuroimaging 2002;12:224-230.

31. Tassi L, Colombo N, Garbelli R, et al. Focal cortical dysplasia: neuropathological subtypes, EEG, neuroimaging and surgical outcome. Brain 2002;125:1719-1732.

32. Salanova V, Andermann F, Olivier A, et al. Occipital lobe epilepsy: electroclinical manifestations, electrocorticography, cortical stimulation and outcome in 42 patients treated between 1930 and 1991. Brain 1992;1156:1655-1680.

33. Salanova V, Morris HH, Van Ness PC, et al. Comparison of scalp electroencephalogram with subdural electrocorticogram recordings and functional mapping in frontal lobe epilepsy. Arch Neurol 1993;50:294-299.

34. Williamson PD, Thadani VM, Darcey TM, et al. Occipital lobe epilepsy: clinical characteristics, seizure spread patterns, and results of surgery. Ann Neurol 1992;31:3-13.

35. Palmini A, Andermann F, Dubeau F, et al. Occipitotemporal epilepsies: evaluation of selected patients requiring depth electrodes studies and rationale for surgical approaches. Epilepsia 1993;34:84-96.

36. Laskowitz DT, Sperling MR, French JA, D'Connor MJ. The syndrome of frontal lobe epilepsy: characteristics and surgical management. Neurology 1995;45:780-787.

37. Morris HH, Dinner D, Luders H, et al. Supplementary motor area seizure: clinical and electrographic findings. Neurology 1998;38:1075-1088.

38. Blume WT, Young GB, Lemieux JF. EEG morphology of partial epileptic seizures. Electroencephalogr Clin Neurophysiol 1984;57:295-302.

39. Quesney LF. Preoperative electroencephalographic investigation in frontal lobe epilepsy: electroencephalographic and electrocorticographic recordings. Can J Neurol Sci 1991;18:559-563.

40. Foldvary N, Klem G, Hammel J, et al. The localizing value of ictal surface EEG in focal epilepsy. Neurology 2001;57: 2022-2028.

41. Lee SK, Kim JY, Hong KS, et al. The clinical usefulness of ictal surface EEG in neocortical epilepsy. Epilepsia 2000;41: $1450-1455$.

42. Pathak P, Blume WT. Asymmetrical epileptogenicity of brain lesions. Epilepsia 1997;38(suppl 8):64.

43. Swartz BE, Halgren E, Delgado-Escueta AV, et al. Neuroimaging in patients with seizures of probable frontal lobe origin. Epilepsia 1989;30:547-558.

44. Henry TR, Sutherling WW, Engel J Jr, et al. Interictal metabolism in partial epilepsies of neocortical origin. Epilepsy Res 1991;10:174-182.

45. Spencer SS. The relative contributions of MRI, SPECT, and PET imaging in epilepsy. Epilepsia 1994;35(suppl 6):72-89.

46. Wieser HG, Hajek M. Frontal lobe epilepsy: compartmentalization, presurgical evaluation, and operative results. In: Jasper $\mathrm{HH}$, Riggio S, Goldman-Rakic PS, eds. Epilepsy and the functional anatomy of the frontal lobe. New York: Raven Press, 1995:297-319.

47. Radtke RA, Hanson MW, Hoffman JM, et al. Positron emission tomography: comparison of clinical utility in temporal lobe and extratemporal epilepsy. J Epilepsy 1994;7:27-33.

48. Swartz BE, Brown C, Mandelkern MA, et al. The use of 2-deoxy-2[ $\left[{ }^{18} \mathrm{~F}\right]$ fluoro-D-glucose (FDG-PET) positron emission tomography in the routine diagnosis of epilepsy. Mol Imaging Biol 2002;4:245-252. 
49. Da Silva EA, Chugani DC, Muzik O, Chugani HT. Identification of frontal lobe epileptic foci in children using positron emission tomography. Epilepsia 1997;38:1198-1208.

50. Chugani HT, Shields WD, Shewmon DA, et al. Infantile spasms: PET identifies focal cortical dysgenesis in cryptogenic cases for surgical treatment. Ann Neurol 1990;27:406-413.

51. Plotkin $M$, Amthauer $H$, Merschhemke $M$, et al. Use of statistical parametric mapping of (18)F-FDG-PET in frontal lobe epilepsy. Nuklearmedizin 2003;42:190-196.

52. Carne RP, O'Brien TJ, Kalipatrick CJ, et al. MRI-negative PET-positive temporal lobe epilepsy: a distinct surgically remediable syndrome. Brain 2004;127:2276-2285.

53. Casse R, Rowe CC, Newton M, et al. Positron emission tomography and epilepsy. Mol Imaging Biol 2002;4:338-351.

54. O'Brien TJ, So EL, Mullan BP, et al. Subtraction ictal SPECT co-registered to MRI improves clinical usefulness of SPECT in localizing the surgical seizure focus. Neurology 1998;50:445-454.

55. O'Brien TJ, So EL, Mullan BP, et al. Subtraction peri-ictal SPECT is predictive of extratemporal epilepsy surgery outcome. Neurology 2000;50:1668-1677.

56. O'Brien TJ, So EL, Cascino GD, et al. Subtraction SPECT coregistered to MRI in focal malformations of cortical development: localization of the epileptogenic zone in epilepsy surgery candidates. Epilepsia 2004;45:367-376.

57. Marks DA, Katz A, Hoffer P, Spencer SS. Localization of extratemporal epileptic foci during ictal single photon emission computed tomography. Ann Neurol 1992;31:250-255.

58. Ho SS, Berkovic SF, Newton MR, et al. Parietal lobe epilepsy: clinical features and seizure localization by ictal SPECT. Neurology 1994;44:2277-2284.

59. Laich E, Kuzniecky R, Mountz JM, et al. Supplementary sensorimotor area epilepsy. Seizure localization, cortical propagation and subcortical activation pathways using ictal SPECT. Brain 1997;120:855-864.

60. Kaminska A, Chiron C, Ville D, et al. Ictal SPECT in children with epilepsy: comparison with intracranial EEG and relation to postsurgical outcome. Brain 2003;126:248-260.

61. Won HJ, Chang KH, Cheon JE, et al. Comparison of MR imaging with PET and ictal SPECT in 118 patients with intractable epilepsy. Am J Neuroradiol 1999;20:593-599.

62. Hwang SI, Kim JH, Park SW, et al. Comparative analysis of MR imaging, positron emission tomography, and ictal singlephoton emission CT in patients with neocortical epilepsy. Am J Neuroradiol 2001;22:937-946.
63. Meyer PT, Cortes-Blanco A, Pourdehnad M, et al. Intermodality comparisons of seizure focus lateralization in complex partial seizure. Eur J Nucl Med 2001;28:1529-1540.

64. Allen PJ, Fish DR, Smith SJM. Very high frequency rhythmic activity during SEEG suppression in frontal lobe epilepsy. Electroencephalogr Clin Neurophysiol 1992;82:155-159.

65. Fisher R, Weber W, Lesser R, et al. High-frequency EEG activity at the start of seizures. J Clin Neurophysiol 1992;82: 229-235.

66. Gloor P. Contributions of electroencephalography and electrocorticography to the neurosurgical treatment of the epilepsies. In: Purpura D, Penry J, Walter R, eds. Neurosurgical management of the epilepsies. New York: Raven Press, 1975:59-105.

67. Spencer SS, So NK, Engel J Jr, et al. Depth electrodes. In Engel J Jr, ed. Surgical treatment of the epilepsies. New York: Raven Press, 1993:359-376.

68. Spencer SS, Guimaras P, Katz A, et al. Morphological patterns of seizures recorded intracranially. Epilepsia 1992;33:537-545.

69. Engel J, Crandall PH. Intensive neurodiagnostic monitoring with intracranial electrode. In: Gumnit RJ, ed. Intensive neurodiagnostic monitoring. Advances in neurology. Vol 46. New York: Raven Press, 1986:85-106.

70. Ojemann GA, Engel J. Acute and chronic intracranial recording and stimulation. In: Engel J Jr, ed. Surgical treatment of epilepsies. New York: Raven Press, 1987:263-288.

71. Lieb JP, Engel J, Jann Brown W, et al. Neuropathological findings following temporal lobectomy related to surface and deep EEG patterns. Epilepsia 1981;22:539-549.

72. Park YD, Murro AM, King DW, et al. The significance of ictal depth EEG patterns in patients with temporal lobe epilepsy. Electroencephalogr Clin Neurophysiol 1996;99:412-415.

73. Sveinbjornsdottir S, Duncan JS. Parietal and occipital lobe epilepsy: a review. Epilepsia 1993;34:493-521.

74. Siegel AM, Williamson PD. Parietal lobe epilepsy. In: Williamson AM, Siegel DW, Roberts VM, et al, eds. Neocortical epilepsies. Advances in neurology. Vol 84. Philadelphia: Lippincott Williams \& Wilkins, 2000:189-199.

75. Olivier A, Boling W Jr. Surgery of parietal and occipital lobe epilepsy. In: Williamson AM, Siegel DW, Roberts VM, et al, eds. Neocortical epilepsies. Advances in neurology. Vol 84 Philadelphia: Lippincott Williams \& Wilkins, 2000:533-575. 